\title{
miRNA-183-5p.1 promotes the migration and invasion of gastric cancer AGS cells by targeting TPM1
}

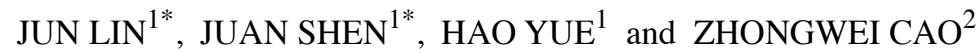 \\ ${ }^{1}$ Department of Pathology, Shanghai General Hospital, Shanghai Jiaotong University School of Medicine, Shanghai 200080; \\ ${ }^{2}$ Department of Gastroenterology, Shanghai General Hospital, Shanghai Jiaotong University School of Medicine, \\ Shanghai 200080, P.R. China
}

Received March 17, 2019; Accepted September 12, 2019

DOI: $10.3892 /$ or.2019.7354

\begin{abstract}
MicroRNA-183 (miR-183) is a small, non-coding RNA that is involved in post-transcriptional processes, is upregulated in gastric cancer and acts as an oncogene in cancer migration. Although fragmentary reports have demonstrated the importance of miR-183 in gastric cancer, its biofunctions and regulatory effects are still unknown. In the present study, the gene and protein expression levels were determined by reverse transcription-quantitative PCR and western blot analysis. The connection between miR-183-5p.1 and tropomyosin 1 (TPM1) was tested through luciferase reporter experiments. Cell viability, apoptosis and related proteins were detected by MTT assay, flow cytometry, immunofluorescence and western blotting, respectively. The migration and invasion of AGS cells modulated by miR-183-5p.1 were analyzed by Transwell assay. TPM1 expression was found to be decreased in gastric cancer tissues and cell lines when compared with normal and adjacent tissues and gastric epithelial cells, and was regulated by miR-183-5p.1 targeting TPM1. miR-183-5p.1 overexpression facilitated the growth and suppressed the death of AGS cells through Bcl-2 and P53 proteins. In addition, miR-183-5p.1 restricted TPM1, TPM2 and TPM3 protein expression in AGS cells. The excessive levels of miR-183-5p.1 promoted the migration and invasion of AGS cells, and inhibited the apoptosis of AGS cells. However, the knockdown of miR-183-5p.1 induced the opposite in AGS cells. In conclusion, miR-183-5p.1 promotes cell proliferation, migration and invasion by downregulating TPM1 and deactivating the Bcl-2/P53 signaling pathways in gastric cancer, indicating
\end{abstract}

Correspondence to: $\mathrm{Dr}$ Zhongwei Cao, Department of Gastroenterology, Shanghai General Hospital, Shanghai Jiaotong University School of Medicine, No. 100 Hai Ning Road, Hongkou, Shanghai 200080, P.R. China

E-mail: zhongweicao09@fudan.edu.cn

${ }^{*}$ Contributed equally

Key words: microRNA-183-5p.1, tropomyosin 1, gastric cancer, cell viability, metastasis that miR-183-5p.1 and TPM1 may be potential targets for the diagnosis or therapy of gastric cancer in the future.

\section{Introduction}

Gastric cancer (GC) is the fourth most commonly diagnosed type of cancers and is the third highest cause of cancer-associated death worldwide, thereby making it a severe public health concern (1). GC most frequently occurs in East Asia and is the second most deadly cancer in China according to recent statistics (2). The multifactorial pathogenesis of GC involves the genetic and epigenetic alterations of oncogenes, tumor-suppressor genes and growth factors involved in GC development (3). Poor early screening results in delayed diagnosis, and currently there are no sufficient therapeutic methods available that can reduce its high death probability. At present, identifying potential molecular targets of the metastatic process is critical for the identification and therapy of GC.

MicroRNAs (miRNAs/miRs), 18- to 22-nucleotide-long non-coding RNAs, are pivotal in post-transcriptional regulation, and mainly bind to the miRNA recognizing elements in the 3'-untranslated region (UTR) to silence the target mRNA and decrease the expression of the corresponding protein (4). miRNAs modulate the expression of their target genes in various diseases including cancer and thereby regulate multitudinous physiological and pathological processes (including occurrence, differentiation, stress response, death and proliferation) (5-9). miRNAs have been reported to cause or suppress tumors, and various miRNAs can be abnormally expressed in different types of cancer, indicating that miRNAs could potentially be applied as cancer diagnostic and treatment strategies (10). Dysregulated miRNAs have been observed in GC and participate in the diffusion, apoptosis, movement and invasion of GC cells by regulating different tumor-related target genes (11-13). The expression of miR-183 was found to be elevated in colon cancer, synovial sarcoma and GC, and this dysregulation was also observed in the corresponding tumor-derived cell lines. For example, miR-183 potentially produces tumors by regulating the tumor-suppressor genes EGRI and PTEN, and the breakdown of this essential miRNA modulation system is probably pivotal to the development of a diverse range of tumors, including colon cancer and synovial sarcoma (14). Previous studies have revealed that miR-183 
may function as an oncogene by regulating $\mathrm{GC}$ cell proliferation, apoptosis and metastasis, and the oncogenic effect of miR-183 may be via directly targeting PDCD4 (15). In addition, miR-183 is downregulated in GC cells and tissues, and inhibits GC cell proliferation and invasion by targeting Bmi-1. Therefore, targeting miR-183 may be a potential therapeutic strategy in GC patients (16). At present, to the best of our knowledge, there have been no reports regarding the roles of tropomyosin (TPM) in GC, but its receptor kinase TPMrelated receptor kinase $\mathrm{B}$ ( $\mathrm{TrkB}$ ) has been shown to promote cell proliferation and invasion, and is associated with the poor prognosis of various malignancies (17). However, TrkA expression is associated with tumor progression and poor survival, and is an independent predictor of poor outcomes in patients with GC (18). In addition, the roles of miR-183 in GC progression are still not completely understood. The aim of the present study was to clarify the influence of miR-183-5p.1 on GC motility as well as the underlying mechanisms.

\section{Materials and methods}

Sample collection. GC samples were collected from 24 GC patients who underwent surgical resection between January 2015 and April 2017 at Shanghai General Hospital, Shanghai Jiaotong University School of Medicine. Patients were aged between 42 and 72 years, with a median of 56 years. All patients gave written informed consent and all protocols were approved by the Ethics Committees of Shanghai General Hospital, Shanghai Jiaotong University School of Medicine (No. 2018KY012).

Cell culture. GES-1 cells and the human GC cell lines MKN-7, AGS and HGC-27 (Cell Resource Center of Shanghai Academy of Sciences, Chinese Academy of Sciences) were cultured in wells or flasks at $37^{\circ} \mathrm{C}$ under $5 \% \mathrm{CO}_{2}$ in Dulbecco's modified Eagle's medium (DMEM; HyClone; GE Healthcare Life Sciences) containing $100 \mu \mathrm{g} / \mathrm{ml}$ streptomycin, $100 \mathrm{U} / \mathrm{ml}$ penicillin, and $10 \%(\mathrm{v} / \mathrm{v})$ fetal bovine serum (FBS; HyClone; GE Healthcare Life Sciences). Cell morphology was observed under an inverted microscope.

Reverse transcription-quantitative PCR (RT-qPCR). All primers for miR-183-5p.1 and TPM1 were synthesized by Invitrogen (Thermo Fisher Scientific, Inc.). Total RNA isolated using TRIzol reagent (Thermo Fisher Scientific, Inc.) was quantified spectrophotometrically. The samples were analyzed on an ABI 7500 RT-PCR device (Applied Biosystems; Thermo Fisher Scientific, Inc.) according to the manufacturer's protocol and GAPDH and U6 genes were used as the internal controls. The primers used for PCR were as follows: TPM1 forward primers, 5'-GCCGACGTAGCT TCT CTGAAC-3' and reverse, 5'-TTTGGGCTCGACTCTCAATGA-3'; GAPDH forward primers, 5'-ATTCCATGGCACCGTCAAGGCTGA-3' and reverse, 5'-TTCTCCATG GTGGTGAAGACGCCA-3'. miR-183-5p.1 RT primer, 5'-GCGAGCACAGA ATTAATACGACTCACTATAGG-3'; miR-183-5p.1 forward, 5'-TATGGCACTGGT AGAATTCACT-3' and reverse, 5'-GCGAGCACAGAATTAATACGAC-3'; U6 forward, 5'-CTCGCTTCGGCAGCACA-3' and reverse, 5'-AACGCTTCACGAATT TGCGT-3'; and GAPDH forward,
5'-CTCAGACACCATGGGGAAGGTGA-3' and reverse, 5'-ATGATCTTGAGGCTGTTGTCATA-3'. All results were quantified using the $2^{-\Delta \Delta \mathrm{Cq}}$ method as previously described (19).

Transfection of miR-183-5p.1 oligonucleotides. The miR-183-5p.1 oligonucleotides were provided by Tiangen Biotech Co., Ltd. GES-1, MKN-7, AGS and HGC-27 cells seeded in 6-well plates (Corning Incorporated) at 50\% confluence were incubated overnight and then transfected with $100 \mathrm{nM}$ miRNA with Lipofectamine 2000 ${ }^{\mathrm{TM}}$ (Invitrogen; Thermo Fisher Scientific, Inc.) for 48 h. miR-183-5p.1 expression was then quantified by RT-qPCR.

Luciferase reporter assay. The target genes of miR-183-5p.1 were predicted by TargetScan (www.targetscan.org/vert_71/) and confirmed by miRBase (www.mirbase.org) or miRecords (mirecords.biolead.org/). A potential target gene, TPM1, was identified. Based on the sequence of TPM1 (National Center for Biotechnology Information Genbank), the 3'-UTR was transformed via amplification and cloning into a specific vector TPM1-UTR-pISo, which was used to build the Luciferase reporter plasmids of WT-TPM1 and MUT-TPM1 mRNAs. After $24 \mathrm{~h}$ of culture, the AGS cells were co-transfected with miR-183-5p.1 inhibitors and mimics using the transfection reagent. The relative luciferase activity of TPM1 was detected via dual-luciferase reporter experiments.

Methyl thiazolyl tetrazolium (MTT) assays. The co-transfected GES-1, MKN-7, AGS, and HGC-27 cells were plated on 96 -well plates $\left(5 \times 10^{3}\right.$ cells/well) for $0,12,24,48$ or $72 \mathrm{~h}$ of culture. After $4 \mathrm{~h}$ of treatment with $20 \mu \mathrm{l}$ of $5 \mathrm{mg} / \mathrm{ml}$ sterilized MTT (Sigma-Aldrich; Merck KGaA) at $37^{\circ} \mathrm{C}$, the incubation medium was changed to $150 \mu \mathrm{l}$ of dimethyl sulfoxide. The absorbance at 490 and $540 \mathrm{~nm}$ was detected via an enzyme-linked immunosorbent assay reader (BioTek Instruments, Inc.). Experiments were conducted in triplicate.

Flow cytometry. GES-1, MKN-7, AGS and HGC-27 cells co-transfected with miR-183-5p.1 mimics and miR-183-5p.1 inhibitors for $24 \mathrm{~h}$ were detected using an Annexin V-FITC Apoptosis kit (BD Biosciences; cat. no. 559763), according to the manufacturer's protocols. Briefly, transfected cells were washed with PBS twice and re-suspended in $100 \mu 11 \mathrm{X}$ binding buffer (BD Biosciences; cat. no. 559763), then incubated for 15 min with Annexin-V/PI (each $5 \mu \mathrm{l}$; BD Biosciences; cat. no. 559763) at $37^{\circ} \mathrm{C}$ in the dark. Finally, $400 \mu 11 \mathrm{X}$ binding buffer was added to each tube and analyzed on a FACS Canto II flow cytometer (BD Biosciences) using FlowJo 7.6 software (Tree Star, Inc.).

Transwell assays. Cell migration and invasion were evaluated in 12-well Transwell chambers with $8.0-\mu \mathrm{m}$ PET film pores (Corning Inc.). Firstly, the lower chamber was filled with $600 \mu \mathrm{l}$ of medium with $10 \%$ FBS as the attracting agent. Then to the upper chamber $100 \mu \mathrm{l}$ of serum-free DMEM with $1 \times 10^{5}$ cells was added, and then incubated for $48 \mathrm{~h}$. The transmigrating cells, after fixation in methanol, staining with $0.2 \%$ gentian violet (m/v; Sigma-Aldrich; Merck KGaA) and washing with PBS, were photographed under an upright microscope, and the number of cells was counted. 
A

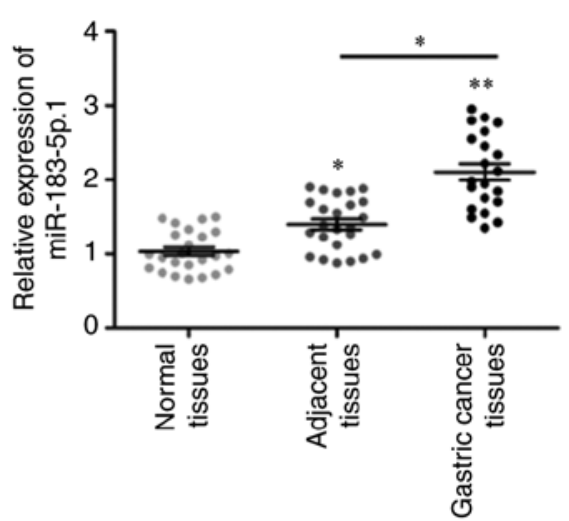

C

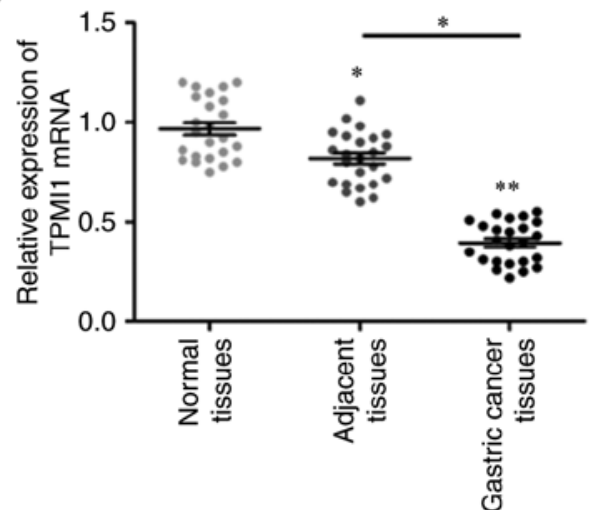

B

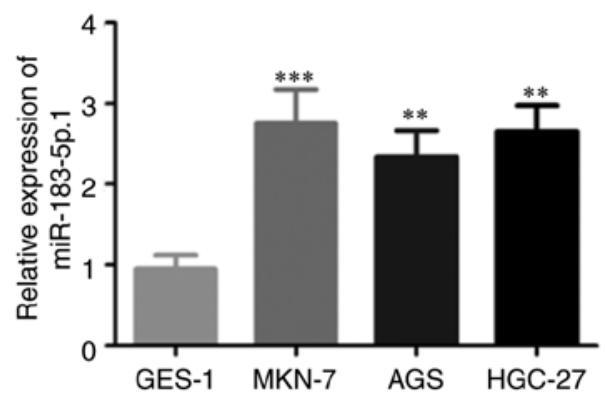

E

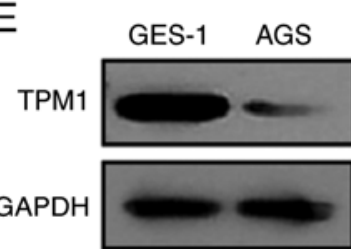

$\mathrm{F}$

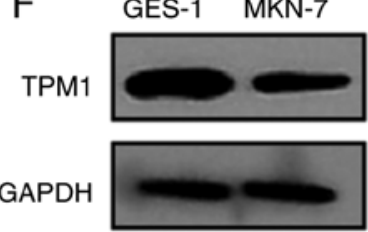

G
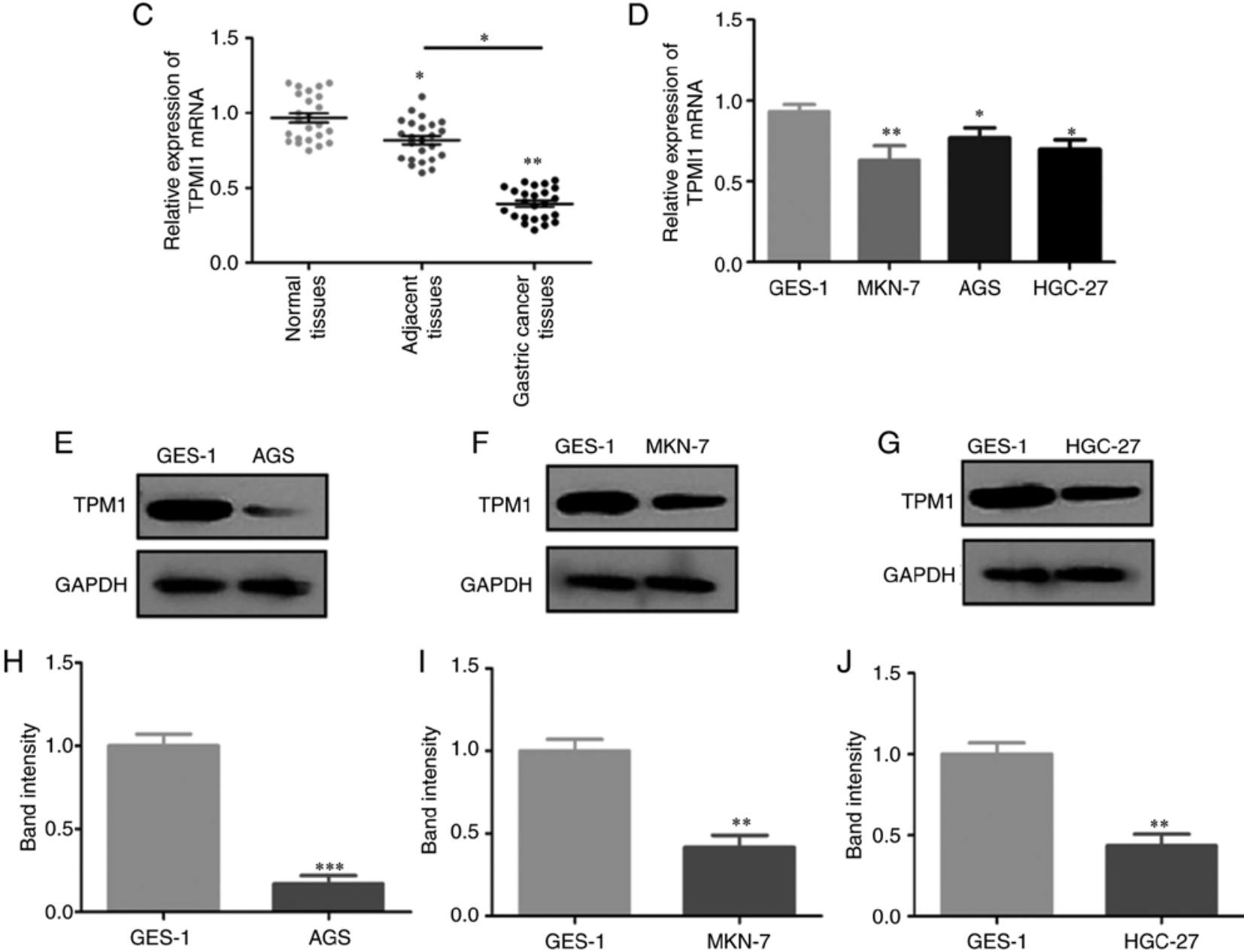

Figure 1. Expression of miR-183-5p.1 and TPM1 in GC cells and tissues. miR-183-5p.1 levels in (A) normal tissues, adjacent tissues, GC tissues and (B) normal gastric epithelial cells (GES-1) and GC cell lines (MKN-7, AGS, HGC-27) were determined by RT-qPCR. TPM1 mRNA expression in (C) normal tissues, adjacent tissues, GC tissues and (D) GES-1, MKN-7, AGS, HGC-27 cells as quantified by RT-qPCR. (E) TPM1 protein expression in GES-1 and AGS cells was determined by western blotting and (H) statistically analyzed. (F) TPM1 protein expression in GES-1 and MKN-7 cells was determined by western blotting and (I) statistically analyzed. (G) TPM1 protein expression in GES-1 and HGC-27 cells was determined by western blotting and (J) statistically analyzed. Results are presented as the mean \pm standard error of the mean $(\mathrm{n}=3){ }^{*} \mathrm{P}<0.05,{ }^{* *} \mathrm{P}<0.01,{ }^{* * * *} \mathrm{P}<0.001$. GC, gastric cancer; RT-qPCR, reverse transcription-quantitative PCR; TPM1, tropomyosin 1; miR, microRNA.

Western blot analysis. After lysis in a radioimmunoprecipitation assay buffer with Roche protease inhibitor cocktail (Roche Diagnosis), total proteins were detected via the bicinchoninic acid method. The supernatant of the cell lysates containing $50 \mu \mathrm{g}$ of protein were run on $10 \%$ SDS-PAGE and then transferred to polyvinylidene difluoride membranes (EMD Millipore). Membranes were cultured with primary antibodies raised against TPM1 (Invitrogen; Thermo Fisher Scientific, Inc.; dilution
1:1,000; cat. no. PA5-29846), TPM2 (Invitrogen; Thermo Fisher Scientific, Inc.; dilution 1:1,000; cat. no. PA5-22012), TPM3 (Invitrogen; Thermo Fisher Scientific, Inc.; dilution 1:1,200; cat. no. PA5-29005), Bcl-2 (Invitrogen; Thermo Fisher Scientific, Inc.; dilution 1:1,200; cat. no. 13-8800), P53 (Invitrogen; Thermo Fisher Scientific, Inc.; dilution 1:1,000; cat. no. MA5-12554) and GAPDH (Invitrogen; Thermo Fisher Scientific, Inc.; dilution 1:2,000; cat. no. PA1-987-HRP), and Goat anti-Rabbit 

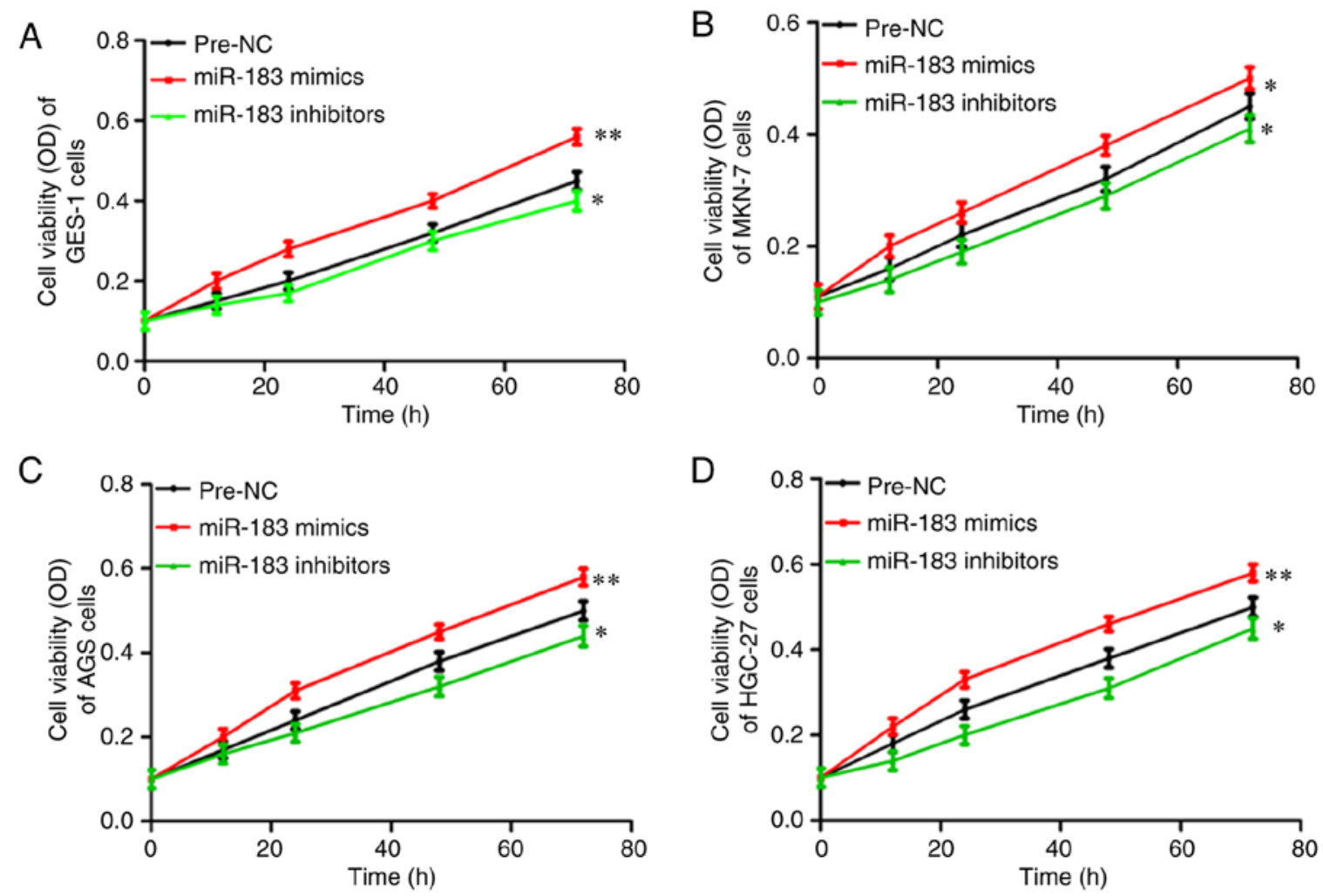

Figure 2. Effect of miR-183-5p.1 on the proliferation of GC cells as determined by MTT assay. miR-183-5p.1 inhibitors and mimics significantly suppressed and promoted, respectively, the cell viability of (A) GES-1, (B) MKN-7, (C) AGS and (D) HGC-27 cells. Results are presented as the mean \pm standard error of the mean $(\mathrm{n}=3) .{ }^{*} \mathrm{P}<0.05,{ }^{* *} \mathrm{P}<0.01$. GC, gastric cancer; miR, microRNA.

IgG (H+L) Cross-Adsorbed Secondary Antibody, horseradish peroxidase (HRP)-conjugated (Invitrogen; Thermo Fisher Scientific, Inc.; dilution 1:2,000; cat. no. G-21234) or Goat anti-Mouse IgG (H+L) Cross-Adsorbed Secondary Antibody, HRP-conjugated (Invitrogen; Thermo Fisher Scientific, Inc.; dilution 1:2,000; cat. no. G-21040) raised against the primary antibodies. Blots were analyzed using the enhanced chemiluminescence matrix. Band intensity was assessed with ImageJ 1.45 software (National Institutes of Health, Bethesda, MD, USA).

Immunofluorescence analysis. The apoptosis of AGS cells transfected with miR-183-5p.1 oligonucleotides was analyzed using a Hoechst 33258 detection kit (Beyotime Institute of Biotechnology; cat. no. C1011) and TUNEL assay (Beyotime Institute of Biotechnology; cat. no. C1089) according to the manufacturer's protocols. After transfection, cells were washed with PBS twice and incubated with Hoechst 33258 reagent $(50 \mu \mathrm{l})$ for $60 \mathrm{~min}$ at $37^{\circ} \mathrm{C}$ in the dark, and then washed with PBS twice. After this, cells were stained with TUNEL solution $(50 \mu \mathrm{l})$ for $60 \mathrm{~min}$ at $37^{\circ} \mathrm{C}$ in the dark and washed with PBS twice. Images were captured and the cells were counted using an Olympus CKX53 inverted fluorescence microscope (magnification, x200). The immunostained sections were evaluated by two independent pathologists.

Statistical analysis. All data were analyzed with SPSS 16.0 (SPSS, Inc.). Statistical analysis was conducted via Student's t-test and one-way analysis of variance with Tukey's post hoc test. The plotting of graphs was conducted on GraphPad
Prism 5.0 (GraphPad Software, Inc.). Results are expressed as the mean \pm standard error of mean. $\mathrm{P}<0.05$ was considered to indicate a statistically significant difference.

\section{Results}

miR-183-5p.1 and TPM1 expression in GC tissues or cells. RT-qPCR revealed that miR-183-5p.1 expression was significantly increased in GC tissues when compared with that noted in the normal or adjacent tissues (Fig. 1A), and increased in MKN-7, AGS and HGC-27 cells when compared with GES-1 cells (Fig. 1B). Notably, TPM1 mRNA expression was decreased in the GC tissues when compared with that in normal or adjacent tissues (Fig. 1C) and in MKN-7, AGS and HGC-27 cells compared with that noted in the GES-1 cells (Fig. 1D). The TPM1 protein expression in AGS, MKN-7 and HGC-27 cells (Fig. 1E-J) was consistent with that observed at the mRNA level.

miR-183-5p.1 modulates the viability of GC cells. The roles of miR-183-5p.1 in regulating cancer were assessed through MTT assays to investigate the viability of the transfected GES-1 (Fig. 2A), MKN-7 (Fig. 2B), AGS (Fig. 2C) and HGC-27 cells (Fig. 2D). The viability of the MKN-7, AGS and HGC-27 cells was significantly enhanced via culture with the miR-183-5p.1 mimics, but was significantly inhibited by miR-183-5p.1 inhibitors.

miR-183-5p.1 targets the TPM1 gene directly in GC. To determine the biofunctions of miR-183-5p.1 in GC, the present study identified the potential target genes of miR-183-5p.1 


\section{A}

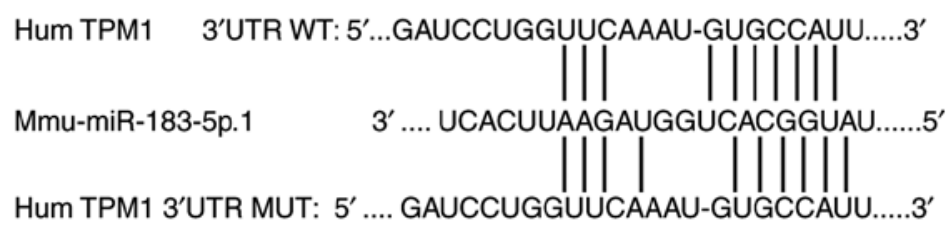

B

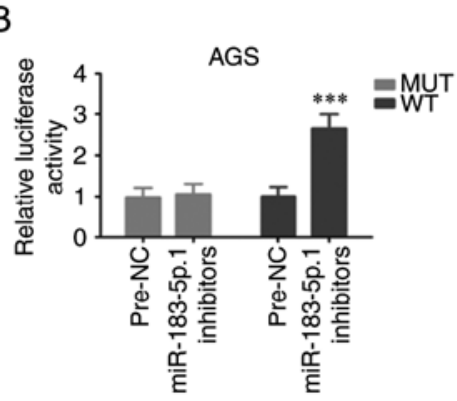

F

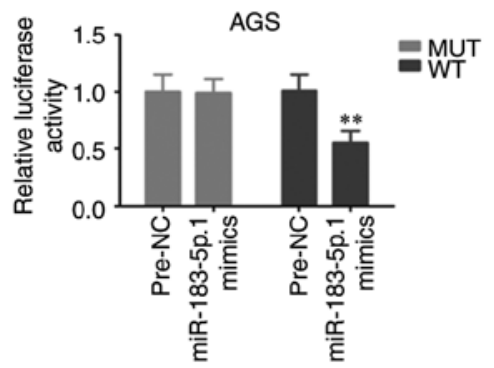

J

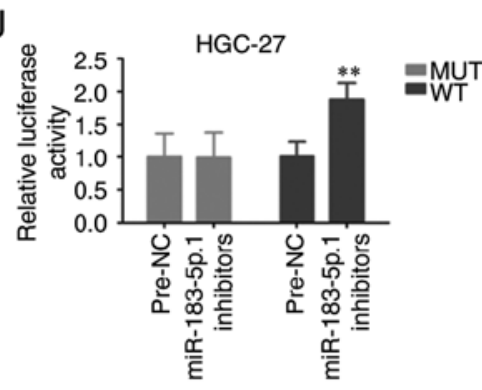

$\mathrm{O}$

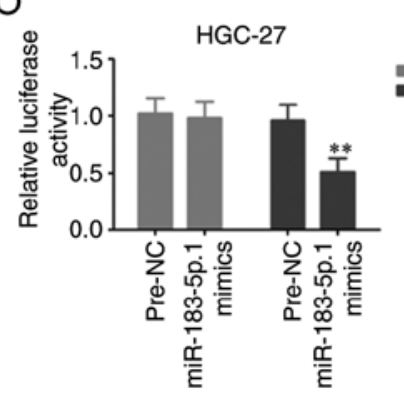

C

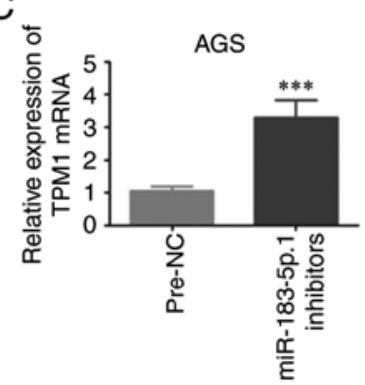

G
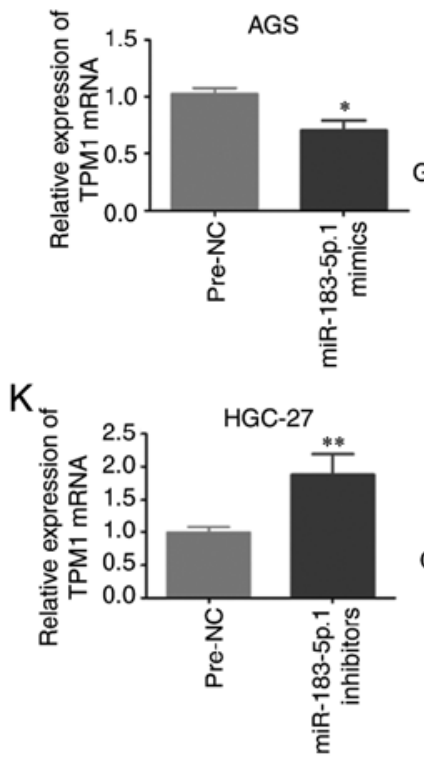

P

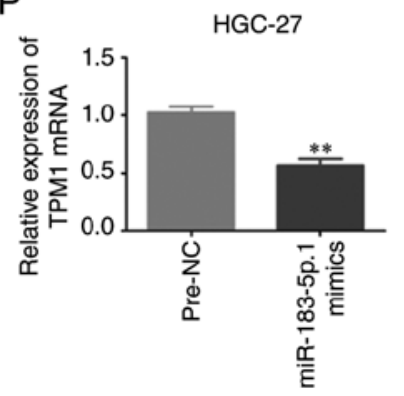

D

miR-183-5p.1

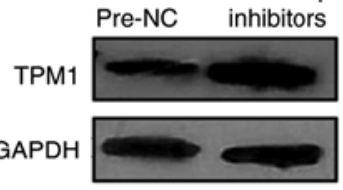

E

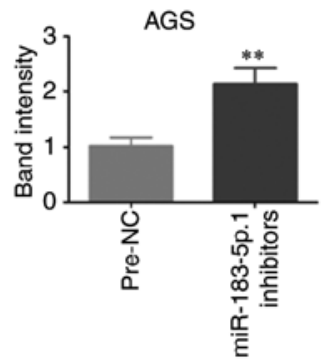

$\mathrm{H}$

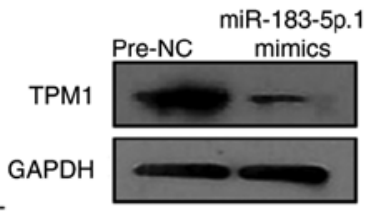

I

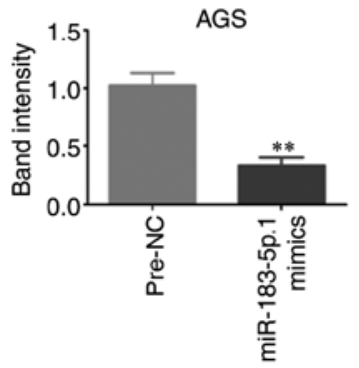

M
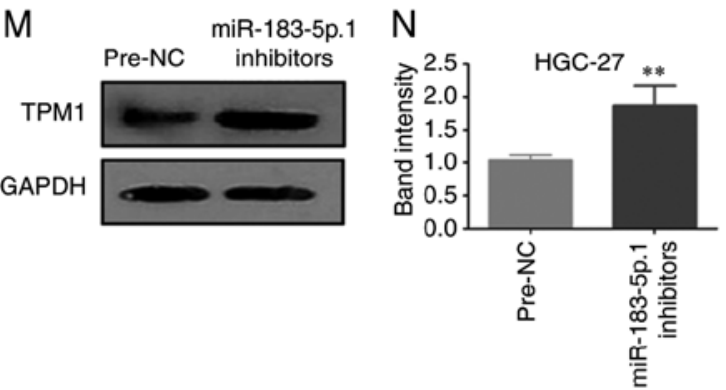

Q

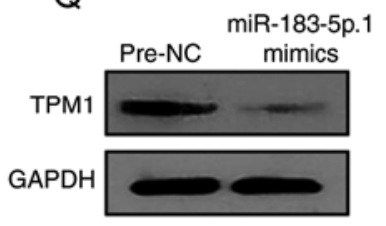

$\mathrm{R}$

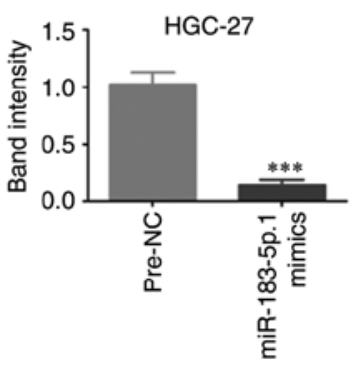

Figure 3. Experimental validation of miR-183-5p.1 as a TPM1 regulator. (A) miR-183-5p.1 binding with the 3'UTR of TPM1 predicted by TargetScan and coding sequence of miR-183-5p.1 and TPM1. The luciferase activities of WT-TPM1 mRNAs in GC (B) AGS and (J) HGC-27 cells were significantly enhanced by transfection with miR-183-5p.1 inhibitors and markedly decreased in (F) AGS and (O) HGC-27 cells by miR-183-5p.1 mimics following the Luciferase reporter assay. TPM1 expression was markedly increased in (C-E) AGS and (K-N) HGC-27 cells by miR-183-5p.1 inhibitors and significantly decreased in (G-I) AGS and (P-R) HGC-27 cells by miR-183-5p.1 mimics as revealed by reverse transcription-quantitative PCR and western blotting. GAPDH served as the internal control. Results are presented as the mean \pm standard error of the mean $(\mathrm{n}=3)$. ${ }^{*} \mathrm{P}<0.05,{ }^{* *} \mathrm{P}<0.01,{ }^{* * * *} \mathrm{P}<0.001$. TPM1, tropomyosin 1 ; GC, gastric cancer; miR, microRNA; WT, wild-type; UTR, untranslated region.

that were dysregulated in GC using three predictive algorithms: TargetScan, PicTar and MicroCosm. TargetScan showed that TPM1 was a key target gene of miR-183-5p.1, and that miR-183-5p.1 was bound to the 3'UTR of TPM1 (Fig. 3A). The relationship between miR-183-5p.1 and TPM1 was validated through Luciferase reporter assay. Plasmids of TPM1-UTR-pISo (WT) and Mu-TPM1-UTR-pIS0 (MUT) were established and separately transfected into AGS and HGC-27 cells. It was demonstrated that miR-183-5p.1 inhibitors markedly intensified the luciferase activity of 
A
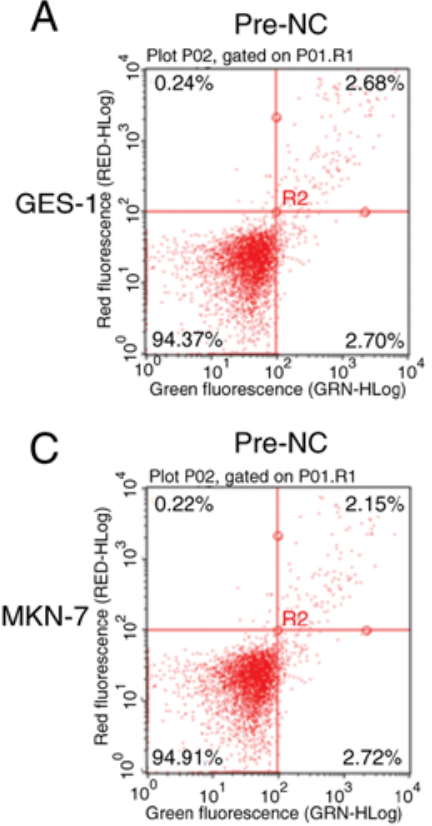

E
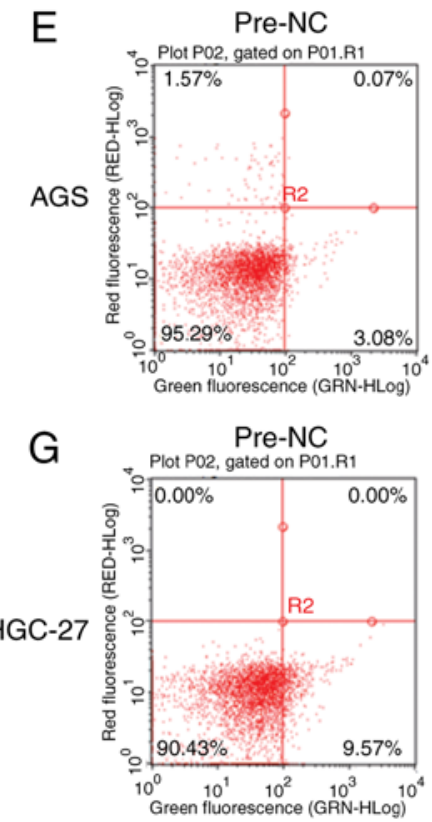

miR-183 inhibitors

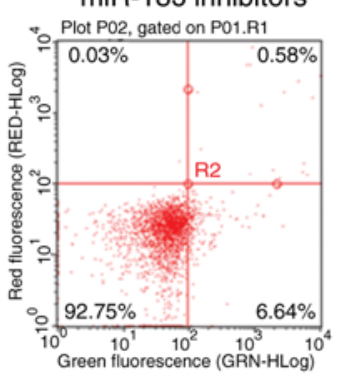

miR-183 inhibitors

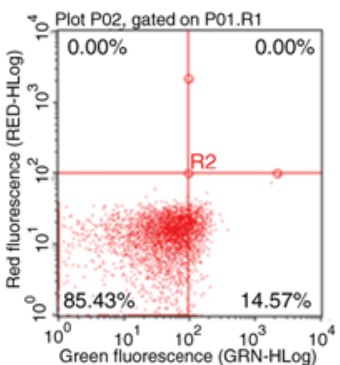

miR-183 inhibitors

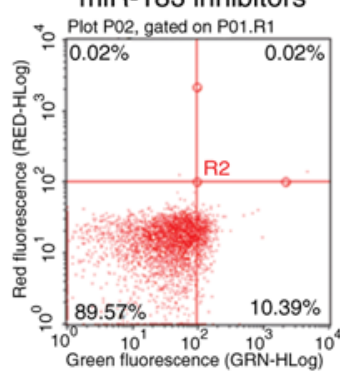

miR-183 inhibitors

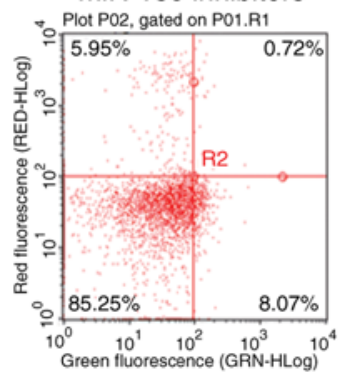

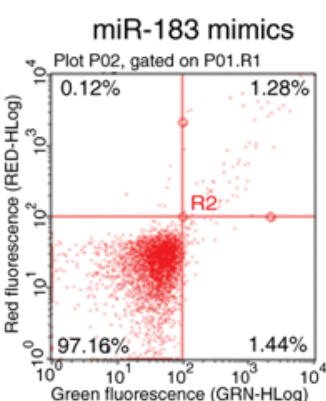

miR-183 mimics

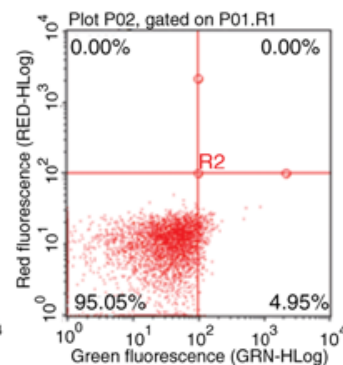

mimics

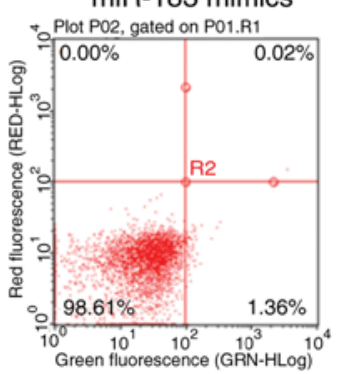

\section{miR-183 mimics}

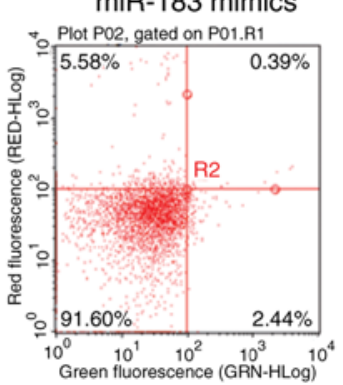

B
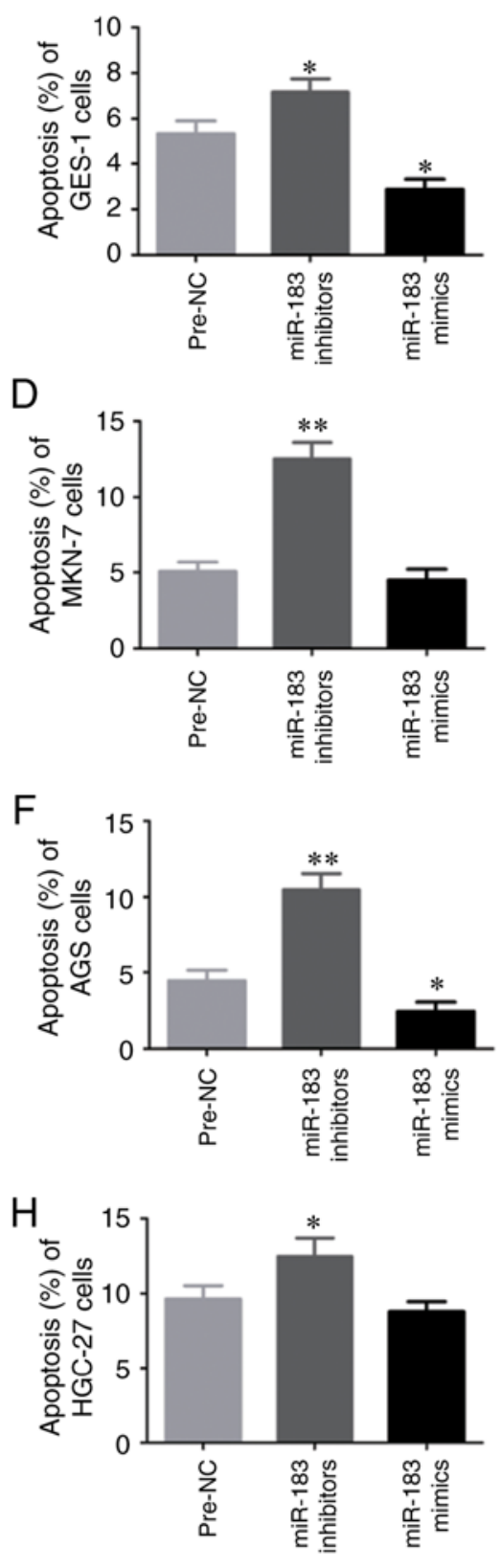

Figure 4. miR-183-5p.1 regulates the apoptosis of GC cells as detected by flow cytometry. miR-183-5p.1 inhibitors increased the apoptosis of (A and B) GES-1, (C and D) MKN-7, (E and F) AGS and (G and H) HGC-27 cells, while miR-183-5p.1 mimics significantly inhibited the apoptosis of (A and B) GES-1, (C and D) MKN-7, (E and F) AGS and (G and H) HGC-27 cells. Results are presented as the mean \pm standard error of the mean $(n=3)$. " $\mathrm{P}<0.05$, ${ }^{* *} \mathrm{P}<0.01$. GC, gastric cancer; miR, microRNA.

TPM1-UTR-pISo (WT; Fig. 3B and J). Furthermore, transfection with miR-183-5p.1 inhibitors markedly elevated TPM1 expression in AGS cells (Fig. 3C-E) and HGC-27 cells (3K-N) at the mRNA and protein levels. Additionally, transfection with miR-183-5p.1 mimics significantly weakened the luciferase activity of TPM1-UTR-pISo (WT; Fig. 3F and O) and TPM1 expression in the AGS cells (Fig. 3G-I) and HGC-27 cells (3P-R). Taken together the results indicate that TPM1 is one of the target genes of miR-183-5p.1.

Apoptosis of GC cells is regulated by miR-183-5p.1. To investigate the function of miR-183-5p.1 in the early and the late apoptosis of GC cells, GES-1, MKN-7, AGS and HGC-27 cell lines were analyzed by flow cytometry. Knockdown of miR-183-5p.1 enhanced the early and the late apoptosis of GES-1 cells (Fig. 4A and B). In addition, the flow cytometry results revealed that the early and the late death of MKN-7 (Fig. 4C and D), AGS (Fig. 4E and F) and HGC-27 (Fig. 4G and $\mathrm{H}$ ) cells was promoted by the knockdown of miR-183-5p.1, while the early and the late apoptosis of GES-1 (Fig. 4A and B) and AGS cells (Fig. 4E and F) was significantly inhibited by the overexpression of miR-183-5p.1.

Expression of TPM2 and TPM3 is affected by miR-183-5p.1. The protein expression of TPM 2 and TPM 3 was analyzed by western blot analysis. The expression of TPM2 and TPM3 

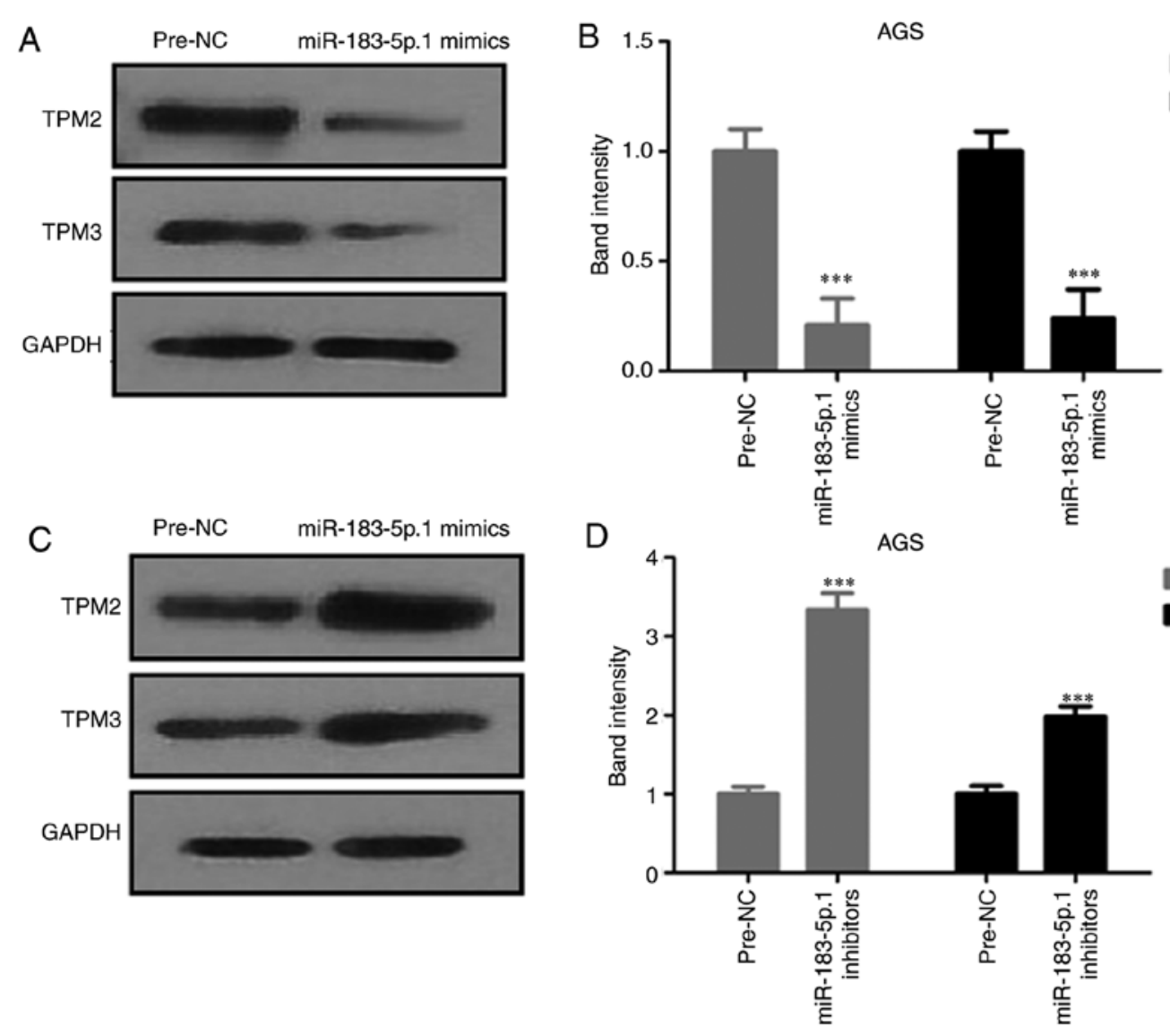

Figure 5. Effect of miR-183-5p.1 on the expression of TPM2 and TPM3 in GC AGS cells. (A and B) miR-183-5p.1 mimics downregulated the expression of TPM2 and TPM3 as determined by western blotting. (C and D) miR-183-5p.1 inhibitors promoted the expression of TPM2 and TPM 3 as detected by western blotting. Results are presented as the mean \pm standard error of the mean $(n=3) .{ }^{* * *} \mathrm{P}<0.001$. GC, gastric cancer; miR, microRNA; TPM, tropomyosin.
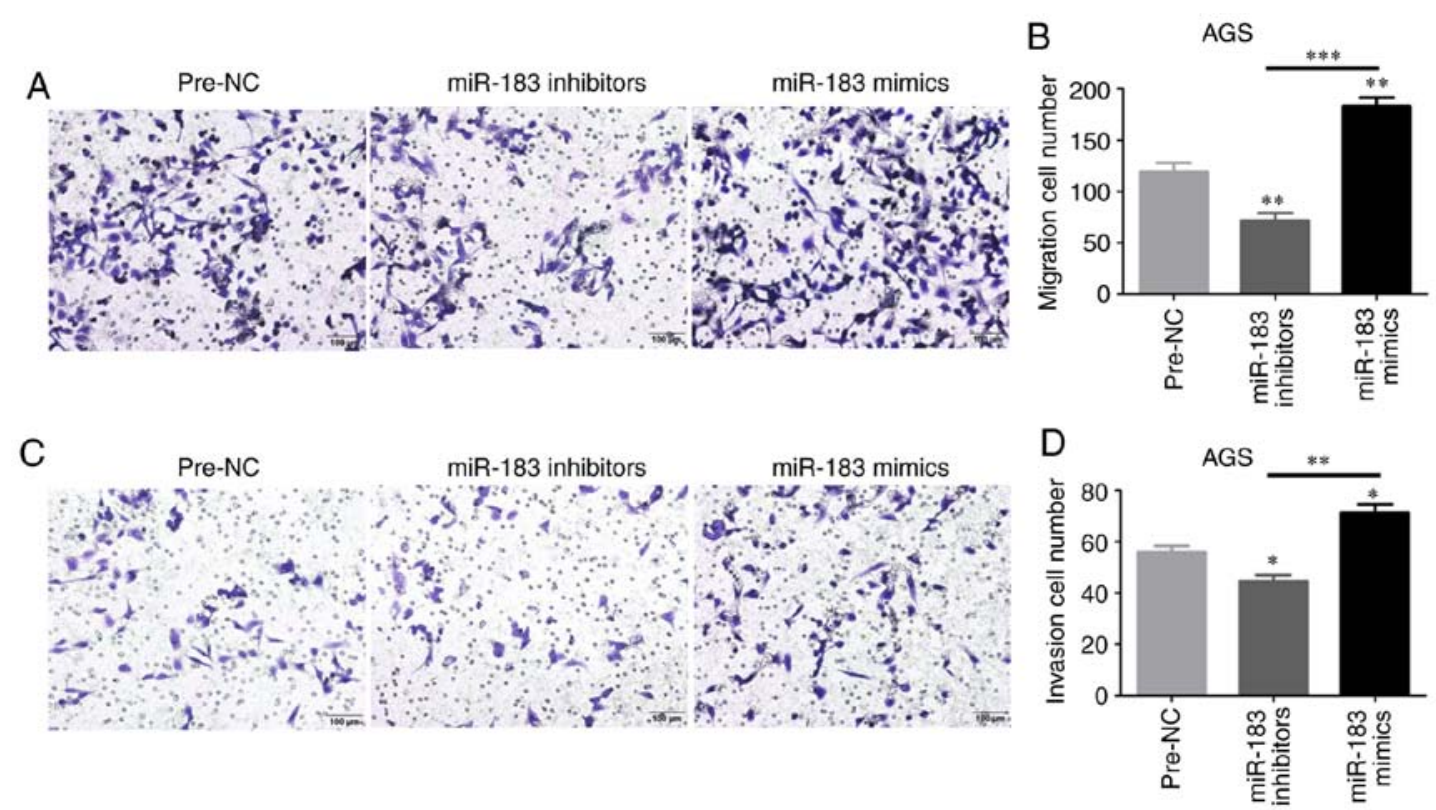

Figure 6. Functional assays of miR-183-5p.1-transfected GC AGS cells. Transfection of the miR-183-5p.1 mimics promoted the (A and B) migration ability and $(\mathrm{C}$ and $\mathrm{D})$ invasiveness of AGS cells as determined by Transwell assays. Results are presented as the mean \pm standard error of the mean $(\mathrm{n}=3)$. ${ }^{*} \mathrm{P}<0.05$, ${ }^{* *} \mathrm{P}<0.01,{ }^{* * *} \mathrm{P}<0.001$. GC, gastric cancer; miR, microRNA.

proteins were decreased in AGS cells after transfection with miR-183-5p.1 mimics(Fig.5A andB), and significantlyincreased after the knockdown of miR-183-5p.1 (Fig. 5C and D).
Cell migration and invasion are promoted by miR-183-5p.1. The regulatory effects of miR-183-5p.1 on GC cell migration and invasion were evaluated through Transwell assays. The 

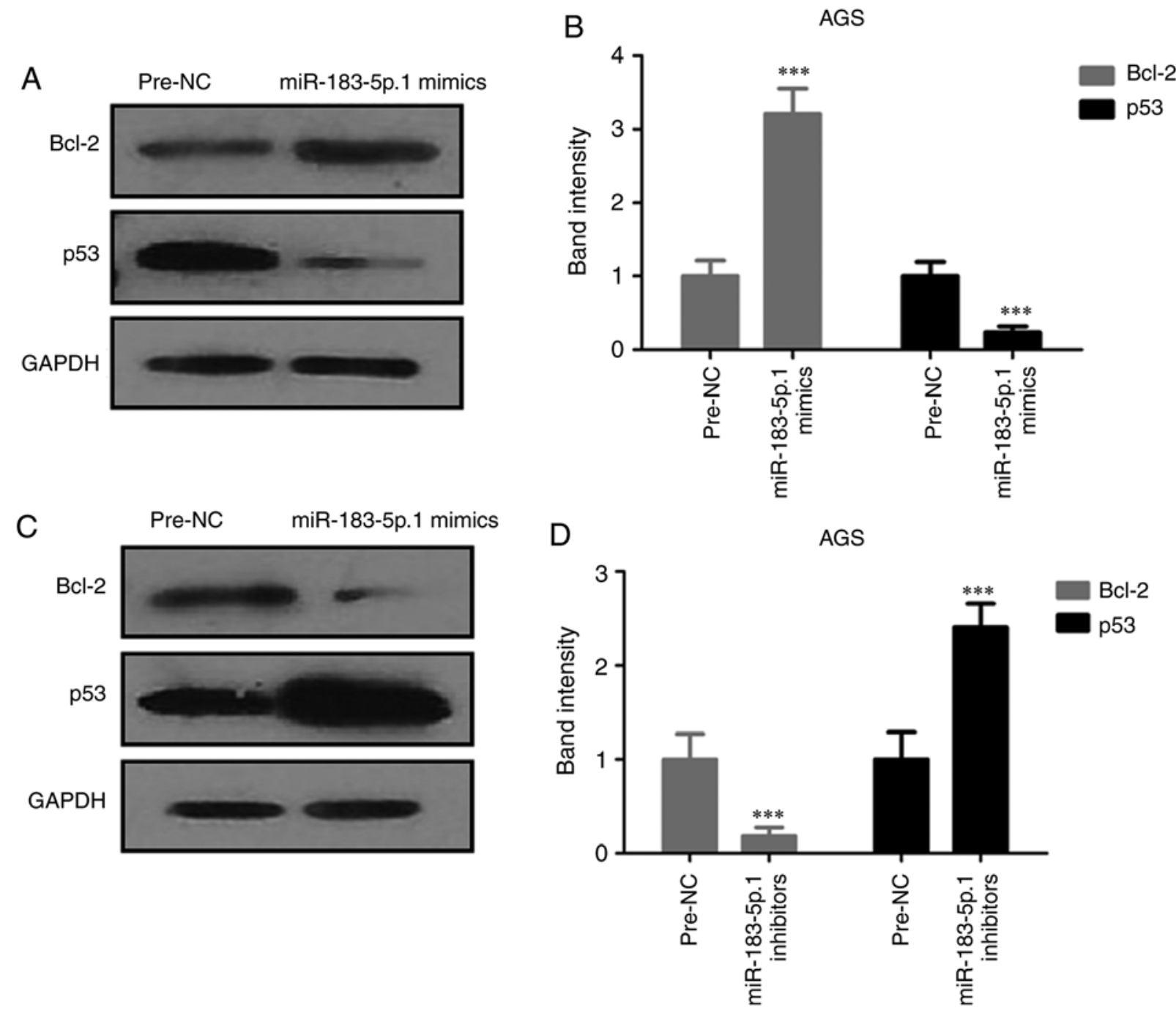

Figure 7. Effect of miR-183-5p.1 overexpression on the expression of apoptosis-associated proteins in GC AGS cells as detected by western blot analysis. (A and B) P53 was decreased and Bcl-2 was increased in the miR-183-5p.1 mimic-transfected cells. (C and D) miR-183-5p.1 inhibitors significantly inhibited the expression of Bcl-2, but significantly enhanced the expression of p53. GAPDH was used as the internal control. Results are presented as the mean \pm standard error of the mean $(n=3) .{ }^{* * *} \mathrm{P}<0.001$. GC, gastric cancer; miR, microRNA.

migration of AGS cells was enhanced in the mimics groups at $24 \mathrm{~h}$ (Fig. 6A and B), but was weakened in the inhibitor groups. In addition, the invasion of AGS cells was validated by Transwell assays (Fig. 6C and D). These results indicated that miR-183-5p.1 could effectively promote GC cell migration and invasion, and that the frequent metastasis of GC may be explained by the mechanism that miR-183-5p.1 mimics stimulate the upregulated bio-properties of GC cells.

Expression of Bcl-2 and p53 in AGS cells. Since miR-183-5p.1 was found to be capable of regulating the migration and invasion of tumor cells through TPM1 protein, the present study detected the expression of apoptosis-related proteins Bcl-2 and p53 through western blotting (Fig. 7A-D). The experiments demonstrated that p53 was significantly increased and Bcl-2 was significantly decreased in the miR-183-5p.1-knockdown cells. However, miR-183-5p.1 overexpression had the opposite effect on the expression of Bcl-2 and p53. These results indicated that the overexpression of miR-183-5p.1 suppressed the death of AGS cells.
Apoptotic analysis of AGS cells by immunofluorescence. After AGS cells were transfected with miR-183-5p.1 mimics and miR-183-5p.1 inhibitors, the apoptosis of AGS cells was detected using Hoechst 33258 and TUNEL detection kits. The results revealed that the apoptosis of AGS cells was induced significantly (Fig. 8A and B) in the AGS cells transfected with miR-183-5p.1 inhibitors, while the overexpression of miR-183-5p.1 suppressed the apoptosis of the AGS cells (Fig. 8C and D).

\section{Discussion}

miR-183, one of the developmentally conserved miRNAs (including miR-96/miR-182) that is located on human chromosome 7q32.3, may play key cellular roles in tumorigenesis (20). miR-183 is abnormally upregulated in leukemia and hepatic cancers as well as other types of cancer (21-24). However, miR-183 expression was decreased and was inversely related to the metastasis of breast and lung cancers (25). Furthermore, miR-183 downregulation has been linked with metastatic lung 
A
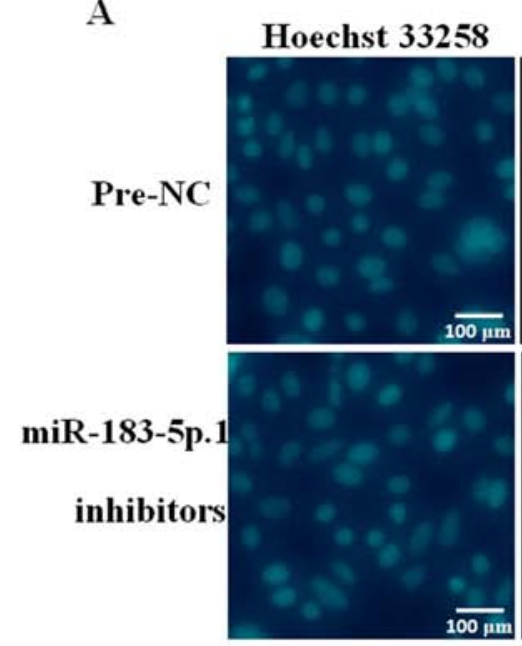

C

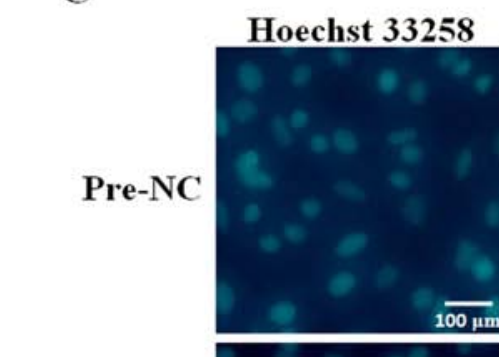

TUNEL
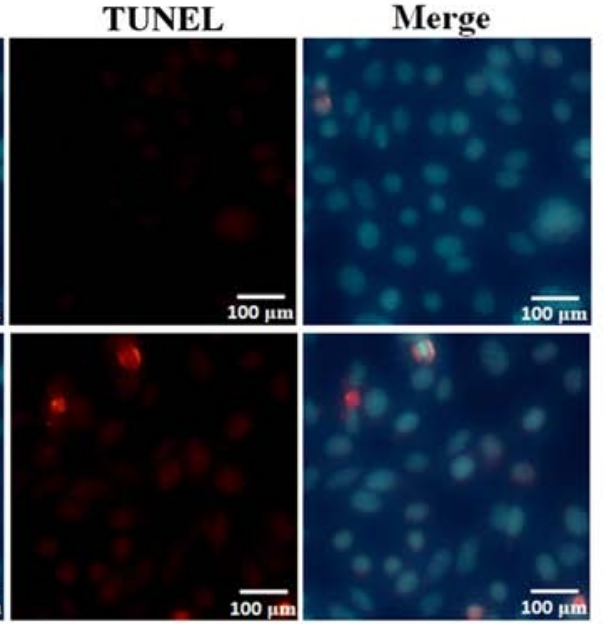

TUNEL

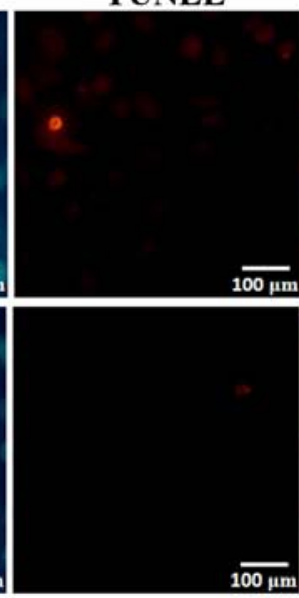

Merge

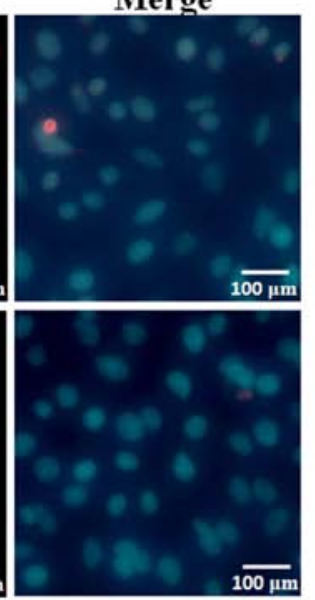

B

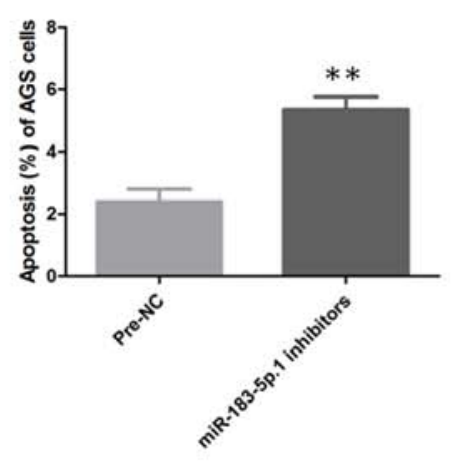

D

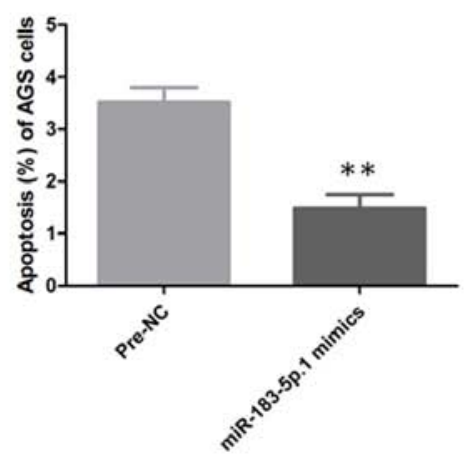

Figure 8. Expression of miR-183-5p.1 and the apoptosis of GC AGS cells as analyzed by immunofluorescence. (A) The knockdown of miR-183-5p.1 promoted the apoptosis of AGS cells as determined by Hoechst 33258 and TUNEL assays. (B) Statistical results of apoptosis. (C) The overexpression of miR-183-5p.1 inhibited the apoptosis of AGS cells as determined by the Hoechst 33258 and TUNEL methods. (D) Statistical results of apoptosis. Results are presented as the mean \pm standard error of the mean $(\mathrm{n}=3)$. ${ }^{* *} \mathrm{P}<0.01$. GC, gastric cancer; miR, microRNA.

cancer, and its excessive expression was found to suppress the invasion of cancer cells (26), indicating that miR-183 may be involved in cancer occurrence, migration or spread and play an antitumor role. The present study revealed that miR-183-5p.1 expression was markedly increased and both TPM1 mRNA and protein expression were significantly decreased in GC tissues and cell lines. However, the dual-luciferase reporter analysis indicated that miR-183-5p.1 targets the 3'UTR of TPM1.

TPMs, a large group of actin-connecting proteins, have $\sim 40$ different isoforms that are critical in diverse actin-based procedures (27). TPMs are expressed in non-muscle cells, irrespective of their molecular mass, including TPM1, TPM2 and TPM3 (28). TPMs as a tumor-associated protein family have been investigated widely and play critical roles in stress fiber modulation and actin cytoskeleton modification, which are closely associated with tumor-specific variations in actin filament aggregation. A growing body of evidence has indicated that the migratory and invasion ability of tumor cells is enhanced by the destruction of stress fibers and by TPM-mediated relevant adhesive structures (29-32). The present study also investigated the influence of miR-183-5p.1 and TPM1 knockdown on AGS cells. TPM1 expression in AGS cells after transfection with miR-183-5p.1 mimics and inhibitors markedly decreased and increased in vitro at the mRNA and protein levels, respectively. However, the transfection of miR-183-5p.1 inhibitors increased the expression of TPM2 and TPM3, and the trend in expression alterations was the opposite after transfection with miR-183-5p.1 mimics. TPM2 and TPM3 are isoforms of TPM1 and are coded by the same gene TPM. We used three software programs, TargetScan, miRBase and miRecords, to predict the targets of miR-183-5p.1, and found that miR-183-5p.1 could bind sites in TPM1 and TPM3. But based on the pros and cons of software forecasting, we investigated TPM1 in this study. In addition, in the present study, the expression levels of TPM2 and TPM3 proteins were also affected by the abnormal expression of miR-183-5p.1. We believe that TPM2 and TPM3 are the targets of our follow-up study. Moreover, these specific impact mechanisms still need to be investigated in depth in subsequent research.

Recent studies have demonstrated that TPM1 as a critical antitumor gene is downregulated in various solid tumors, including breast cancer, colon cancer and urinary bladder carcinoma (33-35). Recent research has confirmed the antitumor role of TPM1 in breast cancer cells (36). TPM1 is necessary for 
the formation of stress fibers, and reduction in cell motility and migration. Activation of the Ras-ERK signaling pathway inhibits the TGF- $\beta$ induction of stress fibers by suppressing the expression of TPM, leading to a more motile and invasive phenotype (37). In addition, TPM1 overexpression was found to induce the apoptosis and inhibit the invasion of renal cancer cells (38). Although a number of experiments have indicated the tumor-suppressor role of TPM1 in various tumor types, the underlying mechanism of its tumor-suppressor gene functions is still unknown.

The present study discovered that transfection with miR-183-5p.1 inhibitors largely weakened the survival of AGS cells and promoted apoptosis, but the opposite results were observed after transfection with miR-183-5p.1 mimics. Similarly, increased AGS cell migration and invasion after transfection with miR-183-5p.1 mimics was significantly promoted by the concurrent siRNA-mediated knockdown of TPM1. According to the above results, we speculate that miR-183-5p.1 targets TPM1 to enhance cell survival, motion and invasion, and reduces cell death in GC cells. Notably, miR-183 was significantly decreased in GC cells and inhibited the invasion of GC indicating that miR-183 may act as a tumor suppressor in GC, partially at least via regulation of Ezrin as previously reported (39). We assessed different targets of miR-183, but these two target genes TPM1 and Ezrin play different roles in GC. In addition miR-183 was investigated by Cao et al (39), but in our study we studied the function of miR-183-5p.1 although they both belong to miR-183 family. However, these arguments warrant further in-depth research for confirmation.

Further analysis of apoptotic signaling proteins revealed that Bcl-2 and P53 participated in the effects of miR-183-5p.1 and TPM1 on AGS cells, suggesting that the inhibitory effect of miR-183-5p.1 on TPM1 expression may be associated with the activation of apoptotic signaling pathways. However, the present study did not identify which apoptosis-related gene was regulated by miR-183-5p.1 or TPM1, and also did not determine the mechanism of miR-183-5p.1 and TPM underlying the regulation of apoptosis-related genes. The apoptosis-related genes involved in the regulation of miR-183-5p.1 and TPM should be investigated in the future, and the mechanisms underlying miR-183-5p.1 and TPM regulation of apoptosis-related genes should also be further investigated.

In conclusion, TPM1 functions as an antitumor gene in GC. Determination of the function of miR-183-5p.1 in GC suggests an important method with which to identify potential markers of GC metastasis and efficient molecular targets for GC treatment.

\section{Acknowledgements}

Not applicable.

\section{Funding}

No funding was received.

\section{Availability of data and materials}

All results and data generated or analyzed during the present study are included in this published article or are available from the corresponding author on reasonable request.

\section{Authors' contributions}

$\mathrm{JL}$ and $\mathrm{ZC}$ conceived and designed all experiments in this study. JS, JL and HY performed the experiments and analyzed all data. JL and ZC drafted and revised this article. All authors have read and approved the final manuscript and agree to be accountable for all aspects of the research in ensuring that the accuracy or integrity of any part of the work are appropriately investigated and resolved.

\section{Ethics approval and consent to participate}

The present study was approved by the Ethics Committee of the Shanghai General Hospital, Shanghai Jiaotong University School of Medicine. Written informed consent was obtained from all patients.

\section{Patient consent for publication}

Not applicable.

\section{Competing interests}

The authors declare that they have no competing interests.

\section{References}

1. Torre LA, Bray F, Siegel RL, Ferlay J, Lortet-Tieulent J and Jemal A: Global cancer statistics, 2012. CA Cancer J Clin 65: 87-108, 2015.

2. Chen W, Zheng R, Baade PD, Zhang S, Zeng H, Bray F, Jemal A, Yu XQ and He J: Cancer statistics in China, 2015. CA Cancer J Clin 66: 115-132, 2016.

3. Otani K,Li X,Arakawa T, Chan FK and Yu J: Epigenetic-mediated tumor suppressor genes as diagnostic or prognostic biomarkers in gastric cancer. Expert Rev Mol Diagn 13: 445-455, 2013.

4. Wu S, Huang S, Ding J, Zhao Y, Liang L, Liu T, Zhan R and He X: Multiple microRNAs modulate p21Cip1/Waf1 expression by directly targeting its 3 'untranslated region. Oncogene 29: 2302-2308, 2010

5. Carleton M, Cleary MA and Linsley PS: MicroRNAs and cell cycle regulation. Cell Cycle 6: 2127-2132, 2007.

6. Boehm M and Slack FJ: MicroRNA control of lifespan and metabolism. Cell Cycle 5: 837-840, 2006.

7. Baltimore D, Boldin MP, O'Connell RM, Rao DS and Taganov KD: MicroRNAs: New regulators of immune cell development and function. Nat Immunol 9: 839-845, 2008.

8. Bartel DP: MicroRNAs: Genomics, biogenesis, mechanism, and function. Cell 116: 281-297, 2004.

9. Garzon R, Calin GA and Croce CM: MicroRNAs in cancer. Annu Rev Med 60: 167-179, 2009.

10. Croce CM: Causes and consequences of microRNA dysregulation in cancer. Nat Rev Genet 10: 704-714, 2009.

11. Yang TS, Yang XH, Wang XD, Wang YL, Zhou B and Song ZS: MiR-214 regulate gastric cancer cell proliferation, migration and invasion by targeting PTEN. Cancer Cell Int 13: 68, 2013.

12. Hsu KW, Wang AM, Ping YH, Huang KH, Huang TT, Lee HC, Lo SS, Chi CW and Yeh TS: Downregulation of tumor suppressor MBP-1 by microRNA-363 in gastric carcinogenesis. Carcinogenesis 35: 208-217, 2014.

13. Song JH and Meltzer SJ: MicroRNAs in pathogenesis, diagnosis, and treatment of gastroesophageal cancers. Gastroenterology 143: 35-47.e2, 2012.

14. Sarver AL, Li L and Subramanian S: MicroRNA miR-183 functions as an oncogene by targeting the transcription factor EGR1 and promoting tumor cell migration. Cancer Res 70: 9570-9580, 2010.

15. Li C, Deng L, Zhi Q, Meng Q, Qian A, Sang H, Li X and Xia J: MicroRNA-183 functions as an oncogene by regulating PDCD4 in gastric cancer. Anticancer Agents Med Chem 16: 447-455, 2016. 
16. Xu L, Li Y, Yan D, He J and Liu D: MicroRNA-183 inhibits gastric cancer proliferation and invasion via directly targeting Bmi-1. Oncol Lett 8: 2345-2351, 2014.

17. Tanaka K, Shimura T, Kitajima T, Kondo S, Ide S, Okugawa Y, Saigusa S, Toiyama Y,Inoue Y, Araki T, et al: Tropomyosin-related receptor kinase $\mathrm{B}$ at the invasive front and tumour cell dedifferentiation in gastric cancer. Br J Cancer 110: 2923-2934, 2014.

18. Kamiya A, Inokuchi M, Otsuki S, Sugita H, Kato K, Uetake H, Sugihara K, Takagi Y and Kojima K: Prognostic value of tropomyosin-related kinases $\mathrm{A}, \mathrm{B}$, and $\mathrm{C}$ in gastric cancer. Clin Transl Oncol 18: 599-607, 2016.

19. Livak KJ and Schmittgen TD: Analysis of relative gene expression data using real-time quantitative PCR and the 2(-Delta Delta C(T)) method. Methods 25: 402-408, 2001.

20. Pierce ML, Weston MD, Fritzsch B, Gabel HW, Ruvkun G and Soukup GA: MicroRNA-183 family conservation and ciliated neurosensory organ expression. Evol Dev 10: 106-113, 2008.

21. Bandrés E, Cubedo E, Agirre X, Malumbres R, Zárate R, Ramirez N, Abajo A, Navarro A, Moreno I, Monzó M and García-Foncillas J: Identification by real-time PCR of 13 mature microRNAs differentially expressed in colorectal cancer and non-tumoral tissues. Mol Cancer 5: 29, 2006.

22. Motoyama K, Inoue H, Takatsuno Y, Tanaka F, Mimori K, Uetake H, Sugihara K and Mori M: Over- and under-expressed microRNAs in human colorectal cancer. Int J Oncol 34: 1069-1075, 2009.

23. Agirre X, Jiménez-Velasco A, San José-Enériz E, Garate L, Bandrés E, Cordeu L, Aparicio O, Saez B, Navarro G, Vilas-Zornoza A, et al: Down-regulation of hsa-miR-10a in chronic myeloid leukemia CD $34^{+}$cells increases USF2-mediated cell growth. Mol Cancer Res 6: 1830-1840, 2008.

24. Ladeiro Y, Couchy G, Balabaud C, Bioulac-Sage P, Pelletier L, Rebouissou S and Zucman-Rossi J: MicroRNA profiling in hepatocellular tumors is associated with clinical features and oncogene/tumor suppressor gene mutations. Hepatology 47: 1955-1963, 2008.

25. Macedo T, Silva-Oliveira RJ, Silva VAO, Vidal DO, Evangelista AF and Marques MMC: Overexpression of mir-183 and mir-494 promotes proliferation and migration in human breast cancer cell lines. Oncol Lett 14: 1054-1060, 2017.

26. Wang G, Mao W and Zheng S: MicroRNA-183 regulates Ezrin expression in lung cancer cells. FEBS Lett 582: 3663-3668, 2008

27. Gunning PW, Hardeman EC, Lappalainen P and Mulvihill DP Tropomyosin-master regulator of actin filament function in the cytoskeleton. J Cell Sci 128: 2965-2974, 2015.
28. Zare M, Jazii FR, Soheili ZS and Moghanibashi MM Downregulation of tropomyosin-1 in squamous cell carcinoma of esophagus, the role of Ras signaling and methylation. Mol Carcinog 51: 796-806, 2012.

29. Redwood C and Robinson P: Alpha-tropomyosin mutations in inherited cardiomyopathies. J Muscle Res Cell Motil 34: 285-294, 2013.

30. Perry SV: Vertebrate tropomyosin: Distribution, properties and function. J Muscle Res Cell Motil 22: 5-49, 2001.

31. Pawlak G and Helfman DM: Cytoskeletal changes in cell transformation and tumorigenesis. Curr Opin Genet Dev 11: 41-47, 2001.

32. Helfman DM, Flynn P, Khan P and Saeed A: Tropomyosin as a regulator of cancer cell transformation. Adv Exp Med Biol 644: 124-131, 2008

33. Bharadwaj S and Prasad GL: Tropomyosin-1, a novel suppressor of cellular transformation is downregulated by promoter methylation in cancer cells. Cancer Lett 183: 205-213, 2002.

34. Raval GN, Bharadwaj S, Levine EA, Willingham MC, Geary RL, Kute T and Prasad GL: Loss of expression of tropomyosin-1, a novel class II tumor suppressor that induces anoikis, in primary breast tumors. Oncogene 22: 6194-6203, 2003.

35. Pawlak G, McGarvey TW, Nguyen TB, Tomaszewski JE, Puthiyaveettil R, Malkowicz SB and Helfman DM: Alterations in tropomyosin isoform expression in human transitional cell carcinoma of the urinary bladder. Int J Cancer 110: 368-373, 2004

36. Dube S, Yalamanchili S, Lachant J, Abbott L, Benz P, Mitschow C, Dube DK and Poiesz BJ: Expression of tropomyosin 1 gene isoforms in human breast cancer cell lines. Int J Breast Cancer 2015: 859427, 2015.

37. Bakin AV, Safina A, Rinehart C, Daroqui C, Darbary H and Helfman DM: A critical role of tropomyosins in TGF-beta regulation of the actin cytoskeleton and cell motility in epithelial cells. Mol Biol Cell 15: 4682-4694, 2004

38. Wang J, Guan J, Lu Z, Jin J, Cai Y, Wang C and Wang F: Clinical and tumor significance of tropomyosin-1 expression levels in renal cell carcinoma. Oncol Rep 33: 1326-1334, 2015.

39. Cao LL, Xie JW, Lin Y, Zheng CH, Li P, Wang JB, Lin JX, Lu J, Chen QY and Huang CM: miR-183 inhibits invasion of gastric cancer by targeting Ezrin. Int J Clin Exp Pathol 7: 5582-5594, 2014.

This work is licensed under a Creative Commons Attribution-NonCommercial 4.0 International (CC BY-NC 4.0) License. 